\title{
Sectors and Strategies of Global Communications Regulation*
}

\author{
Bernd Holznagel and Raymund Werle
}

\begin{abstract}
As the global communication network matures, the systems and procedures for regulating the growing network and its use are being challenged. The general proliferation of services or the specific demand for electronic transactions require guidance and control which the market alone cannot supply. Meanwhile, traditional regulatory regimes remain far from global or coherent. This article distinguishes between coordination and regulation to clarify areas where government intervention is unnecessary and where indispensable. It explores the current patchwork of regulatory approaches, reviews different regulatory areas and strategies, identifies trends, and highlights problem areas particular to electronic commerce and third party protection.
\end{abstract}

\section{Introduction}

It is undisputed that globalization relies to a considerable degree on information and communication technology. Innovation in this area continues to reinforce the process of globalization. The Internet is, of course, the most prevalent case of this reinforcing phenomenon. In the course of the past ten years or so it has grown out of its original role as a medium of communication for academic circles in industrialized countries to become an everyday one for private and professional users around the globe. As digital technologies spread, globalization has affected all sectors of the communications industry. A range of new services, such as pay-TV or interac-

Bernd Holznagel is a law professor and director of the Institut für Informations-, Telekommunikationsund Medienrecht (Institute for Information, Telecommunication, and Media Law) (ITM) at the University of Münster, Germany. His research covers areas such as Access Problems in the Multimedia Age, Legal Framework of Data Protection and Data Security, and Regulation of "Old" and "New" Media. He may be reached at <holznagel@uni-muenster.de>.

Raymund Werle is principal research associate with the Max-Planck-Institut für Gesellschaftsforschung (Max Planck Institute for the Study of Societies) in Cologne, Germany. His current research is focused on the interaction of technical and institutional innovations and on the evolution, development, and governance of the Internet. He may be reached at <Werle@ mpi-fg-koeln.mpg.de>. 
tive home shopping, is evolving which challenge the traditional pattern and institutions of content regulation.

Thus, globalization of communications on the basis of digital technology has two crucial dimensions: an infrastructure dimension that involves the technical network and a content and services dimension that involves the usage of the infrastructure. We can observe processes of industrial restructuring in either dimension. Small start-ups have developed into giants and achieved dominant market positions: Cisco Systems, the manufacturer of Internet routers, is a prominent example. New corporations such as Vodafone in the area of mobile telephony have taken over competitors in order to increase market share and offer services in all parts of the world. Most spectacular have been mergers which created global players that cover every step in the media production and distribution chain. America Online combined forces with Time Warner and Viacom merged with CBS creating vertical conglomerates that are able to provide and transmit in their own networks comprehensive multimedia content and services for the world market. 'The regulatory implications and consequences of these developments are momentous: not so much concerning the basic tasks and objectives of communications regulation which remain basically the same but the more so regarding the scope, the instruments, and the agents of regulation.

The following analysis will mainly focus on the Internet and on Internet-based services but it will also touch briefly upon other sectors of technical communication. It first introduces an analytical distinction of regulation and coordination which helps to assess where public intervention is required and where private initiative will provide solutions. In a second step specific areas of regulation will be examined in order to identify the relevant strategies and institutions shaping these strategies. Then, by looking at a perspective for global communications regulation, we will attempt to classify our findings and find trends in regulation. Some final remarks will refer to the future role of the law.

\section{Coordination and Regulation}

A complex communication system or infrastructure such as the Internet can be regarded as an opportunity structure which provides various options to exchange data and content in different forms and at different levels of technical quality and sophistication. Making use of these options and developing them further requires to some degree concerted action on the side of equipment manufacturers, network operators, service providers, users and public agencies at the national and increasingly at the international level. The action aims at steering and guiding the development and use of the infrastructure to the benefit of the actors involved or affected.

Concerning the type of action we can draw an analytical distinction along different dimensions between regulation and coordination (Schmidt and Werle, 1998: chapter 4; Werle, 2001a). In Table 1 we illustrate this distinction by focusing on technical and economic aspects of the infrastructure. The dimensions of action include the aim, the mode and the means as well as the economic effect of concerted action.

Coordination aims at achieving compatibility or frictionless interoperation of technical components which includes users' easy access to the network. It is at- 
TABLE 1

Steering Technical Infrastructure: An Analytical Distinction of Types of Action

\begin{tabular}{lll}
\hline & Coordination & Regulation \\
\hline Aim & $\begin{array}{l}\text { Interoperation of technical } \\
\text { components in "networks," } \\
\text { compatibility }\end{array}$ & $\begin{array}{l}\text { Prevention of negative } \\
\text { externalities of technology }\end{array}$ \\
Mode & $\begin{array}{l}\text { Voluntary negotiated agreements, } \\
\text { market processes }\end{array}$ & $\begin{array}{l}\text { Political imposition, hierarchical } \\
\text { political governance }\end{array}$ \\
Means & Conventions, contracts, standards & $\begin{array}{l}\text { Legal rules, political ordinances } \\
\text { Effect }\end{array}$ \\
\hline
\end{tabular}

tained on the basis of negotiated agreements or through market processes and takes the form of contracts or likewise of (compatibility) standards. The (intended) effect of coordination is a reduction of transaction costs. Frequently another effect is that positive externalities are generated. That means that users, but also service providers or other "participants" in the network, increasingly take advantage of the network's growth without having to pay for this additional benefit.

Regulation aims at preventing negative externalities such as technical accidents, electronic intrusion into privacy, infringements of (intellectual) property rights or, more generally, over-utilization of a common pool resource (Ostrom, 1990). The means of regulation are legal rules or political ordinances. They are hierarchically imposed by governments or other political authorities. The (intended) effect of regulation is the internalization of the negative externalities by those who have induced them.

Clearly, the incentive structure of coordination differs fundamentally from that of regulation. Equipment manufacturers, network operators, service providers, and users usually share an interest in reducing transaction costs. In network technologies, these costs tend to be very high unless agreements are reached, for example, on the use of common standards. Although the existence of such a common interest does not rule out a situation in which preferences are split as to the best solution, a common solution is likely to evolve. A solution can emerge either as a consensual agreement that is negotiated by actors who acknowledge their interdependence or as a de facto convention that emerges in the market. The solutions tend to be selfenforcing, i.e. they enjoy a considerable likelihood of compliance.

In contrast, regulation depends on some kind of political authority to be enacted and to become effective. Actors who benefit from the provision and use of a product or service will not be inclined to bear costs or other burdens voluntarily which, as a side effect of their activities, are incurred by third parties who are not directly involved but (negatively) affected by these transactions. Thus, political imposition of regulations appears to be necessary to avoid negative externalities.

Put in game theoretic terms, coordination is often akin to the "battle of the sexes" in which actors strive for a common solution but initially disagree as to which 
particular solution to choose. Regulation, on the other hand, shows features of a "prisoners' dilemma" in which incentives to cooperate are so weak that, as a rule, no common socially beneficial solution is achieved voluntarily (Snidal, 1985). The latter problem can only be overcome in a "collaborative regime" which is based on enforceable agreements secured by hierarchical political governance. Coordination in contrast can be achieved on a voluntary basis. In this case a "coordinative regime" facilitates institutionalized self-coordination by providing opportunities to communicate and to negotiate a common solution (Stein, 1990).

This distinction of coordination and regulation looks at costs and benefits from a rational perspective focusing on interest and utility. But regulation, which often takes the form of legal rules or law, also engages normative considerations and touches upon social values which are symbolized and reinforced by these rules. "Content" regulation-for instance, focusing on what is communicated or broadcasted via the channels of a network-is usually based on normative rather than economic or commercial criteria. It should also be emphasized that the distinction between regulation and coordination is not a binary one. Specific measures to shape and channel the development and use of technical infrastructures often blend elements of coordination and regulation. But the analytical distinction helps to assess if an intervention of governments or public agencies in shaping the development and use of an infrastructure is unnecessary (coordination) or indispensable (regulation).

\section{Areas and Strategies of Regulation}

\section{Provision and Operation of Networks}

Worldwide communication requires as its backbone a global technical infrastructure. The Internet provides such an infrastructure. Its generic protocol stack TCP/IP runs "on top" of technologically heterogeneous telephone and data networks, fixed as well as wireless. While providing transparent transmission of all kind of digital information (so called end-to-end transparency), TCP/IP also allows a broad range of programs and procedures to be run on the application layer, virtually without any technical or organizational restriction.

This flexibility notwithstanding, the majority of telephone networks - and many data networks on which TCP/IP runs--evolved before the Internet started to grow and were originally dedicated to other purposes. For many decades these networks were installed and operated by public administrations or private companies which enjoyed a monopoly position within their national confines. Coordination and regulation were inseparable. At the international level, however, the national monopolies had to reach agreements in order to facilitate transnational communication. These agreements included the allocation of frequencies, the development of an international telephone numbering scheme or the adoption of interface standards to secure frictionless interconnection of national networks. Some of the issues addressed at the international level were regulative but the majority turned out to be coordinative in nature. Failure to coordinate policies on noninterference of frequencies and on the compatibility of national networks would have resulted in disadvantages for all nations involved. Therefore, the need of a common solution was 
rarely contentious. But more often than not there was disagreement as to which coordinative solution to choose because the economic benefits of different solutions were asymmetrically distributed (Krasner, 1991).

Traditionally, broadcasting frequencies are allocated to nation states by the International Telecommunication Union (ITU). As a part of the United Nations system, this international organization also allocates and coordinates the cross-border use of these frequencies at a global level. The determination of frequencies issued by the ITU takes the form of treaties that are binding under international law for the member states of the ITU. Coordination of telephone and data networks is facilitated mainly through technical standards that are adopted as recommendations. No network operator is obliged to implement the standards but once adopted, they are likely to diffuse internationally (Holznagel, Enaux, and Nienhaus, 2001: 205-211; also Genschel and Werle, 1993).

Since liberalization, the ITU and other "official" international and regional organizations of telecommunications coordination have lost leverage. Non-governmental organizations (NGO) such as industry consortia and forums provide technical standards to coordinate the operation of networks and the provision services. Some of these organizations are quite exclusive but many rely on broad memberships (Werle, 2001b). The existence and market success of their standards-either complementary to, or in competition with "official" ones-proves that indeed coordination can be achieved without the involvement of governments or other public actors.

Due to the decentralized structure of the Internet, the use of uniform and open standards is of particular importance. Only in the days of the Internet's forerunner Arpanet could standards be hierarchically imposed. Switching from an earlier network control protocol to TCP/IP was mandated by the U.S. Department of Defense (DOD) through its Advanced Research Project Agency (ARPA) back in 1982 (Norberg and O'Neill, 1996: 183-196). Beginning in 1985, after the period of absolute governance and ownership by the DOD, the network was opened up to develop into an academic and research network. In the decade from 1985 to 1995 , when the U.S. National Science Foundation funded the central components of the Internet, two organizations evolved which have provided the vast majority of standards used in the Internet.

The first is the Internet Engineering Task Force (IETF). Participation in the IETF and its numerous working groups is open to anyone and a broad and unrestricted discussion of proposals via electronic mailing lists is possible. To be adopted as a standard at least two independent working implementations must have been completed. The standards are accepted on the basis of consensus and published online in the so-called Request for Comments (RFC) series. The standards are available free of charge, as are those adopted by the World Wide Web Consortium (W3C). The $\mathrm{W} 3 \mathrm{C}$ is the other decisive Internet standardization organization focusing on components and applications of the World Wide Web. Basically all standards of the web architecture that are of relevance today have been developed by the W3C. Like the IETF the $\mathrm{W} 3 \mathrm{C}$ is a non-commercial organization of volunteers, but the volunteers are organizations rather than individuals as is the case with the IETF. Meanwhile the $\mathrm{W} 3 \mathrm{C}$ includes some 500-member organizations-companies from the industry and service sectors as well as research and education institutions. Standards are also adopted on the basis of consensus although in cases in which consen- 
sus turns out to be difficult to achieve Tim Berners-Lee, one of the inventors of the WWW who is heading the W3C, appears to have the final say (Gillies and Cailliau, 2000).

Technical standardization of the TCP/IP-based Internet and the World Wide Web has remained a coordinative task. Direct intervention into the standardization process by governments or other public agents was not necessary. However, some organizational and secretarial costs of the IETF have been covered by public funds. Governmental support facilitating rather than determining technical coordination as a bottom up process may indeed be needed to avoid under-provision of coordinative solutions such as technical standards (Werle, 1995).

Public support may be even more urgently required if and when the transition from an established to a new and better coordinative solution is at stake. Transition is particularly difficult in decentralized systems even if all individuals would benefit from it (Leibenstein, 1984). The new generation of Internet protocols offers a most impressive case in point. After four years of work, the IETF published in 1998 as a draft standard a new Internet protocol, the so-called IP version 6 (or IPv6), also known as IP Next Generation. Ipv6 is regarded as a necessary means to enlarge the address space and to augment Internet functions including a stronger encryption sequence and high quality services needed for sophisticated (real time) applications.

While the development of the new protocol proceeded smoothly within the IETF, the migration from the current Ipv4 to the new version has turned out to be difficult even though Ipv6 is backward compatible (to Ipv4) and even though consensus prevails that the features of Ipv6 are urgently needed. Vendors hesitate to build Ipv6 routers or operating systems as long as users do not have the longer addresses; and users do not demand these addresses as long as no high quality Ipv6 products are available. In turn, these products do not appear on the market as long as operating systems and Ipv6 routers are lacking. Overcoming this "lock-in" of an existing standard (David, 1985) can be facilitated by governmental support.

Recently the European Commission took the initiative to promote switching to Ipv6. Erkki Liikanen, the Commissioner for the Information Society, told an industry task force of Internet service providers, telecommunications operators, equipment suppliers and research networks that it was imperative to swiftly migrate to the new protocol because the Internet might run out of addresses in 2005. This would jeopardize the successful launch of the new generation of mobile communication devices ( $3 \mathrm{G}$, UMTS) because each device requires its own address to be integrated with the Internet.

The allocation of an unambiguous address (i.e. 32 bit numbers) to each host that is connected to the network at a given time is essential for the routing and transmission of data packets and thus the functioning of the Internet. At the same time, the introduction of a system of domain names which are visible in e-mail and WWW "addresses" as human-friendly identifiers has been seen as important in order to promote the ease of use of the network. Names are easier to remember than numbers. Originally designed to solve a coordination problem, the domain name system (DNS) —especially names in the generic top level domain ".com"-were increasingly regarded as a valuable business resource which could be used as marketing tools and brand names. The process of allocating domain names changed its 
character (Mueller, 2000). It was transformed from an act of coordination to one of resource allocation. This transformation implies negative externalities for those who claim a specific domain name (e.g. trademark owners) but find this name already allocated to somebody else (e.g. a competitor) at low or no cost (originally on a first come first serve basis).

The DNS provides a good example of how coordinative and regulative elements are blended in the governance of the Internet. In Table 1 we have argued that hierarchical political governance is the mode to process regulatory issues. If we look at the organization, which is responsible for the allocation of names in the generic top-level domains, we find a private non-profit corporation incorporated in California-a private organization and not a government or an intergovernmental organization such as the ITU. The Internet Corporation for Assigned Names and Numbers (ICANN) assumed responsibility in 1998 (Mueller, 2000; see <http://www.icann.org/ general/abouticann.htm $>$ for organizational details). ICANN is the successor of the Internet Assigned Names and Numbers Authority (IANA) which worked on the basis of government contracts as a kind of U.S. government agency. After the privatization of the Internet, the U.S. government opted for what has been called "regulated self-regulation" in the area of domain name assignment (Knill and Lehmkuhl, 2002: 53-55). It delegated authority to ICANN while subsequently weakening its own central role in this area. But there remains a hierarchical political element in this arrangement. ICANN operates in "the shadow of the state" from which it has borrowed its authority. Nonetheless ICANN has the capacity to formulate and implement the substantive and procedural rules within its jurisdiction by itself. This includes the capacity to authorize new top-level domains and to establish a dispute resolution mechanism to process conflicts over domain name allocation.

In a certain sense ICANN encompasses the classic state functions of the legislative (i.e. the determination of top level domains), executive (allocation of sub-domains), and judiciary branches. However, any separation of powers is missing as is an unambiguous democratic legitimacy. This is why ICANN has been a magnet for controversy ever since it assumed control of the domain-name system from the U.S. government in 1998. ICANN is accused by different quarters of operating too slowly, of acting in an opaque and arbitrary manner and of ignoring the voices of grass-root civil society groups. Critics argue to strictly limit ICANN's capabilities so that it does not try to regulate Internet content, or get into other areas of regulation such as consumer protection - an indication that ICANN is poised to increasingly take on regulatory functions.

\section{Setting Up a Regime for Global Commercial Transactions}

Another area of coordination and regulation is the use of the technical infrastructure for commercial transactions of information, goods, and services across all borders. It includes establishing markets or, more specifically, establishing a uniform global framework of conditions for electronic commerce that can accommodate a broad spectrum of different business models. The conditions to be created and safeguarded have to meet a number of prerequisites. One of these is that they need to ensure business be done safely and in a secure way over the Internet; another is that the market rules for e-commerce be internally flexible and open for innovation and 
at the same time firm enough to cope with crisis situations and with destructive attacks from external parties. Most of these tasks are regulatory in nature. Thus, political hierarchical governance seems to be indispensable also in this case. The problem is not that such governance structures do not exist. Rather, the problem is that there is more than one such political authority involved in cross border transactions and that the rules which govern the national markets often differ from one country to the other. Only in a limited number of cases can we find internationally shared or accepted rules. Whenever national rules collide at the international level, private actors as well as governments are affected, and common solutions have to be found. These solutions may constitute sector-specific international regimes combining intergovernmental agreements, bilateral contracts, and industry self-regulations.

To be sure, an encompassing global regime governing commercial electronic transactions has not evolved yet, and it is unlikely to evolve. But we can observe a number of rules and regulatory initiatives existing in the United States and in Europe which have the potential to develop into global standards of coordination and regulation of electronic market transactions.

\section{EUROPEAN INITIATIVES}

Prior to the start of any electronic commercial transaction of goods or services a contract has to be concluded. Its negotiation, formation, and performance is of crucial importance in e-commerce. The European Commission has taken the initiative in this area to provide a stable framework for electronic commercial transactions in order to help avoid market failure. In May 2000 the Commission passed the Ecommerce Directive, which had to be transposed into national law by the member states within 18 months. In one of its central parts, the Directive does not directly create new law but determines whose country's law applies if electronic transactions cross the borders of EU member states. According to the Directive, the country-of-origin principle generally applies. Companies selling goods or services electronically are subject to the legal framework of the member state where they are based. The seller's country's law also applies to the customer no matter in which member state of the European Union she lives. In other parts, the Directive establishes far-reaching information requirements aiming to promote the transparency of cross border trade for the consumers. It also provides liability rules that are of paramount importance to Internet Services Providers and other intermediaries in electronic markets.

Apart from binding regulations for contracts and consumer protection, functional market regulation also needs as an integral part a security concept which guarantees the confidentiality and the authenticity of all transmitted data. The conclusion of a contract via the Internet can only form the basis of a business transaction if the parties involved can be sure that they have entered into a contract with the intended party. At the same time the confidentiality of sensitive data must be ensured when transmitted. Cryptography and digital signatures are the key techniques in this area. The latter were subject to the EU-Directive on Electronic Signatures which was adopted in December 1999. Without going into further detail, it should be mentioned that the Directive ties certain legal consequences to the use of a digital signa- 
ture, and seeks to ensure that the party using the signature can be identified and that the user has exclusive control over the certificate. Nearly all member states have implemented the requirements of the EU-Directive into national law. Given that the parties involved in an electronic transaction have a common interest in authenticity securing provisions, it is surprising that a EU-wide market has not yet been established for certification services. One reason may be that the process of harmonization has in fact been delayed because technical standards are still missing as are rules necessary to implement the rather weak requirements of the laws.

All in all the harmonized measures that these European initiatives have adopted for different areas have led to considerable progress on the way to the establishment of a market order for e-commerce. Even if certain areas remain to be regulated, important aspects such as contracts, consumer protection and digital signatures have been dealt with. What is still missing, however, are instruments and rules to protect this market order against criminal acts. Though the European Union has recognized the importance of harmonizing the criminal laws of the member states, binding enforceable rules still do not exist in this field. Thus, the Council of Europe's European Convention on Cybercrime, which was adopted by the EU Council of Ministers, is currently the only substantial initiative in this field.

\section{INITIATIVES IN THE UNITED STATES AND AT THE INTERNATIONAL LEVEL}

Concerning technical and economic developments the United States is ahead of Europe in electronic commerce with regard to the establishment of market rules for e-commerce. The foundations were created by a regulatory framework program developed by the U.S. government in July 1997. It was followed by a number of additional, more limited initiatives that cannot be presented in any detail here. One can say, however, that a fairly comprehensive set of legal-economic rules govern ecommerce in the United States (Perritt, 1996).

But as the Internet is neither exclusively an American nor a European phenomenon a global regulatory framework is needed. The public and private initiatives at the international level have produced a patchwork of rules and recommendations that lacks consistency and comprehensiveness. Intergovernmental and other international organizations, bilateral, and multilateral governmental groups, the TransAtlantic Business Dialogue (with global players such as Bertelsmann and AOL/ Time Warner) as well as the Global Business Initiative have produced all kinds of documents, memorandums, and agreements, the majority of which are not legally binding. They complement existing elements of a better-established rule system for conventional international trade which in principle applies to electronic transactions, too. Taken together they appear as constitutive parts of an emerging international electronic commerce regime which has proved to be effective especially in areas where the problems they address are coordinative rather than regulative.

The regime includes interface solutions such as the safe harbor or the countryof-origin principles which leave contradicting national commerce laws unchanged but facilitate commercial cross border transactions. In creating an international regime, private actors - in the first instance large corporations - are often as influential as, if not more influential than, public actors (Ronit and Schneider 2000). Private actors-in this case "transatlantic stakeholders" such as the Trans-Atlantic Busi- 
ness Dialogue and the Trans-Atlantic Consumer Dialogue-were also involved in the negotiations on an agreement between the United States and the European Commission on "Guidelines for Increased Regulatory Cooperation and Transparency." With a view to the evolving transatlantic electronic marketplace, they were developed in the context of the "Transatlantic Economic Partnership (TEP)" which entails bilateral U.S.-EU actions in the area of technical barriers to trade. The objectives of the legally non-binding Guidelines are to improve cooperation between U.S. and EU regulators and to promote transparency for the public in establishing and amending regulations. They are to "contribute to achieving high levels of protection for health, safety, consumers, and environment" (Guidelines: II 5 a).

\section{Protection of Third Parties}

In a broader sense the establishment of a stable market order for e-commerce in the context of new media and communication technologies also includes measures such as those suggested in the Guidelines to protect health, safety, consumers and environment. These measures often aim at avoiding negative externalities of technology-based transactions and, thereby, protect third parties which may be negatively affected by them although not directly involved in these transactions. In e-commerce especially the aspects of child and data protection have been addressed (Holznagel, 1999). These problems are of a global nature. Documents negatively influencing the moral development of children can easily be spread and personal data can illegally be obtained on a worldwide scale. Reaching international agreements in these areas is difficult not only due to divergent business interests but also due to different ethical and cultural norms and values of the countries involved (Committee to Study Global Networks and Local Values, 2001).

\section{Child Protection}

Early on, Europe addressed the problem of cross border child protection, originally in the area of TV broadcasting. The first Television Directive, issued in 1989, aimed at harmonizing the national regulations that concern child protection across the European Community. More than other regulations, child protection had to bridge considerable differences between single member states. What is considered immoral in Catholic Ireland may very well be compatible with more liberal Dutch moral concepts. Thus, the level of child protection envisaged by the first TV Directive is generally considered to be relatively low. Given this fact, it is not surprising that any European child protection regulation applicable to the Internet is lacking. Thus only national provisions-which are also of limited effect-apply.

As in Europe, child protection has also been an issue in traditional media regulation in the United States. Even the most relevant bill, the Child Pornography Prevention Act of 1996, does not contain any specific rules concerning online activity. Such rules could be found in the Communications Decency Act and the Child Online Protection Act, which did not survive judicial scrutiny. They were overturned because they conflicted with the First Amendment to the U.S. Constitution that gives the value of free speech more weight than essentially any other value (Holznagel, 2000). 
As a result the U.S. legislative and executive branches have opted for "regulation through technical means." They are advocating the use of specific filter systems for the Internet. Users can download these filters free of charge and can install them on their own computer systems. Filtering technology such as the Platform for Internet Content Selection (PICS) developed by the World Wide Web Consortium provides a kind of content labeling infrastructure for the Internet. It enables users to selectively block content. PICS relies on content rating and labeling by Internet content providers, third parties such as government agencies or directly by the users (Resnick and Miller, 1996; <http://www.w3.org/PICS/>). Thus, PICS provides a technology-based solution to a technologically induced problem (Weinberg, 1997). This solution relies on (industry) self-regulation and individual self-determination. Only the general framework for the provision of filtering technology is provided by the government. Filtering technologies usually do not eliminate content from the Internet but only control access to or diffusion of content in the net. Using these technologies adult users can prevent minors from accessing and viewing restricted content.

Apparently child protection cannot be attained at the global level by globally harmonized rules. The European experience in this field has shown that the necessary consensus on uniform values and morals ultimately cannot be achieved even in a single region. The only realistic possibility appears to be a definition of absolute minimum standards, in the area of child pornography for example. This, however, is not so much a problem that is to be dealt with by child protection regulation, but rather falls in the realm of global harmonization of criminal law. A further problem of worldwide child protection is the U.S. reliance on technical solutions for regulation differs fundamentally from the concept and understanding of regulation as it prevails in Europe - even though there are voices, among them the German Bertelsmann-Foundation, which strongly advocate following the U.S. model towards a global commitment to (self-) regulation (Bertelsmann Stiftung, 1999).

\section{Data Protection (Privacy)}

The strict observation of data protection standards is of paramount importance for the functioning of e-commerce (Burkert, 2000). Users, who have to reveal and transmit their credit card numbers and other sensitive information when they engage in e-commerce expect the industry to handle this highly sensitive data in the most cautious and trustworthy way. Frequently, though not always, there is also the provision requiring sensitive information to accomplish online transactions. But business firms can use personal data of their customers for purposes which are in some instances beneficial, in others harmful, and in most cases unknown to them. Individuals want to keep control over the collection and use of personal information to avoid negative effects. It is not contentious that the protection of privacy is a regulative task. The question rather is: Is it primarily a task of governments to provide for the necessary security or can it be done through private industry selfregulation? The European Union and the United States have tackled this issue using different strategies. The United States, to put it simply, prefers industry self-regulation while Europe favors government action (Haufler, 2001: chapter 4). Given these diverging routes towards privacy protection the resulting incompat- 
ibility threatened to significantly reduce the volume of commercial electronic transactions between the two continents. This consequence was eventually avoided through an "interface solution"- the Safe Harbor Agreement which mixes public and private authority (Farrell, 2002).

Apart from bilateral agreements such as that of the Safe Harbor, no privacy agreements have emerged at the global level. There have been discussions of Internet related privacy issues in the context of the G8, the OECD, and the Global Business Dialogue, but neither intergovernmental nor inter-firm decisions of more than symbolic value have been taken.

\section{Current State and Trends of Regulatory Practice}

Not every rule that has been established to control global communications aims at regulating the development and use of communication networks, in particular the Internet. Efforts to adopt rules in order to coordinate the development and use of the Internet are equally important. They help reduce transaction costs and create favorable conditions to generate positive externalities. Often specific policy measures blend regulative and coordinative elements, and they involve public actors and private actors. While public actors are governmental or intergovernmental units private actors can either be business organizations and business associations (including labor unions) or citizens and civil society groups. Traditionally governments have played an important role in the coordination and regulation of communication networks. In many countries telecommunication networks were not only regulated but also operated by public administrations or government agencies. Therefore, it is not surprising to find governments involved in many arenas which deal with the governance of the Internet-regulation as well as coordination.

\section{Areas of Government Intervention}

In the communications sector one can discern two subcategories. On the one hand, we find classic technical regulation such as the allocation of frequencies. In this field the ITU acts as an original intergovernmental law making organization that determines broadcast parameters and frequencies. The member states have to adhere to the ITU regulations when they allocate frequencies nationally. With the Internet we have seen that the allocation of domain names, which entails elements of both coordination and regulation, is administered by ICANN which is a nongovernmental private organization. ICANN claims to represent different types of Internet stakeholders: Individual users, commercial organizations engaged in Internet business and several units of technical coordination. It acts as a central agency according to its own rules. This is a reason why it appears as the core organization of a global regulatory Internet regime (Mueller, 2002: chapter 10), a kind of Internet government. But ICANN acts as we have seen "in the shadow" of the U.S. government. The government can intervene into ICANN's business even though it claims not to intend to do so.

On the other hand, in areas that are less technology focused, we can observe that governments try to accomplish international agreements to facilitate, for instance, commercial electronic transactions. But the results of the international efforts have 
not been very promising. One reason why many efforts have failed may be a lack of creativeness in the high diplomacy settings of international organizations such as the World Trade Organization (WTO). Most regulatory activities in the WTO aim at harmonizing diverging national regulations because globally harmonized regulations are seen as the precondition for international competition and trade (Werle, 2001c). More flexible solutions of the "soft law" type (Abbot and Snidal, 2000) involving private actors and different types of contracts only rarely evolve in the WTO context.

The goal of harmonization also prevails in the European Union. But it is restricted to establishing minimum standards in the areas of e-commerce, child and data protection as well as cybercrime. An early example of this strategy was the first Television Directive. The European strategy of harmonization was successful because the European Union has achieved a deeper form of market integration than the WTO system, given the stronger centralization of political authority and the existence of enforcement mechanisms in the European Union.

\section{Rules to Resolve the Conflict of Laws}

As we lack global regulation and as it remains unlikely that harmonized regulations will be agreed upon at the international level, governments and regional authorities such as the European Commission have to deal with the so called conflict of laws. This conflict arises when the objectives and legal instruments of two different legal systems collide. In these cases conflict of laws rules are needed to establish which law is to take precedence concerning, for example, jurisdiction, enforcement and material law provisions (Osthaus, 2000). Due to its global structure such conflicts of laws are common in the Internet, primarily between the United States and Europe. There are some mechanisms - chiefly in the realm of private law, a few also in public law-which help resolve such conflicts. The international law of civil procedure, for instance, includes rules for the recognition and enforcement of foreign judgments. The Safe Harbor problem, however, shows that not all conflicts of laws can be resolved by resorting to these traditional instruments.

\section{Regulation without Governments}

Internet standardization provides many examples of successful collective action without government intervention. This, however, is an area in which the actors involved directly take advantage of the adoption of common solutions. Technical coordination, which includes collaborative technical development as in the case of Open Source Software of the "Linux" type (Holtgrewe and Werle, 2001), offers beneficial conditions for self-regulation if some regulatory tasks are added to the coordinative ones. Many groups and organizations in the area of technical coordination have developed stable membership rules, procedural and decision rules as well as working routines which facilitate handling regulatory issues, too. Therefore, governments often are well advised to refrain from regulation and provide incentives for self-regulation. Also, as was indicated above, the profound lack of international consensus on important regulatory issues leaves governments no choice. 
They have to support self-regulation if they want an international regulatory framework to be established.

Not only at the international level but also within national confines in which in principle authoritative agencies can foster regulation self-regulation is frequently preferred, in particular in high-tech areas. This applies to technical issues but also to content regulation, where technical devices made available by the industry facilitate user control over content selection. Technical solutions such as PICS (see above) or software tools which help protect privacy of Internet users substitute technology for law and promise to do away with the familiar problems associated with the implementation of legal regulations (Lessig, 1999).

\section{Trends}

If we infer future trends from the current state of regulation, the first suggestion is that we will see few initiatives towards creating a uniform global communication law. Current initiatives are of a rather symbolic nature and are mostly irrelevant for daily practice. One reason is that institutions such as the Global Business Dialogue, which come up with initiatives and proposals, lack the legal authority to enforce these proposals as binding rules. Institutions, such as the UN and its sub-organizations, that are endowed with this legal authority due to their established standing in international law have been rather reluctant to come up with their own proposals. This reluctance has been reinforced by the tendency of the United States to use its de facto veto power to block any regulatory agreement, especially regarding the Internet, to be adopted in the context of the UN and more so of the ITU. The creation of a uniform global legal framework for communication is further complicated by the numerous different interests involved. Countries are generally only willing to cooperate on a limited scale and do not want to give up their fundamental moral principles which have evolved over decades and have shaped the countries' legal systems. Also, for the largest trading powers and trading blocks there is often an incentive and an opportunity to induce global rule changes through unilateral strategies (Cowhey and Richards, 2000).

Given the model of state-oriented communications regulation, expectations that harmonization will take place at the regional level will often be disappointed. Indeed, the "European House" is still being built with remarkable endeavor and the most important element of this process has been harmonizing the EU member states' legal rules. But in particular harmonization in the communications sector does not take us far. The rapid technical developments continue and cause business models in e-commerce and digital television to develop just as fast. Legal provisions are often harmonized far too late. Even more complicated is the situation with the Council of Europe. An agreement has to be negotiated between all member states and then has to be ratified in each member state in a lengthy process which implies considerable time lags. The roughly 27 consecutive drafts of the Convention on Cybercrime can serve as an example here. Harmonization initiatives may be a desirable method to regulate dynamic markets such as the Internet based new economy, but in practice they are not an effective (or readily available) method to solve the problems at hand. 
A final option to achieve global or at least regional regulatory coherence is provided by different variants of self-regulation. We observe a trend towards self-regulation. Self-regulation originally emerged in areas of, primarily technical, coordination when coordinative and regulative purposes were blended. Voluntary standard setting, for instance, responded to concerns of the public regarding technological but also "ethical" risks. In the Internet a code of conduct, the so-called netiquette, evolved which was "standardized" in several documents issued as Requests for Comments (Leib and Werle, 1998). From these technical areas self-regulation diffused into commercial and other areas where profits but also moral values are at stake. Arenas and mechanisms of self-regulation can be found, for example, in the realm of intellectual property where business firms started collaborative initiatives to safeguard property rights. The joint involvement of firms and civil society organizations in content rating and the provision of filter technology in the field of child protection have already been mentioned. Some forms of self-regulation, such as ICANN's domain name allocation and dispute resolution, can be classified as "regulated self-regulation" others, such as those in the area of intellectual property operate outside the "shadow of the state" as "private self-regulation" (Knill and Lehmkuhl, 2002).

But despite all the euphoria concerning the flexibility and openness for innovation of these variants of self-regulation, we should be aware that they have developed because governments have been unable to keep control over technology or have failed to implement legal regulations and, most importantly, have not been able to achieve consensus in international negotiations. However, not only in public regulation but also in private self-regulation problems arise when consensual agreements are to be reached or the implementation of a regulatory scheme by all affected private actors is at stake. This problem is avoided when exclusive "clubs" of the most powerful players, such as international business round tables, issue and implement the rules. But the exclusiveness of these clubs triggers other problems. The clubs lack democratic legitimacy and the regulations they adopt may generate negative externalities, i.e. they are beneficial to the club members but may be unfavorable to others. Such externalities again call for some kind of government intervention.

This brings us back to the public actors and to their capacity to regulate communications. Given the almost insurmountable difficulties to accomplish global regulatory uniformity governments have increasingly focused on developing regional "regulatory blocks" such as the European and the North American regulatory schemes in the area of electronic commerce. The two schemes differ with respect to the legal traditions and the political culture they are embedded in. The governments accept and protect these differences. But more often than not they found ways in terms of interface solutions to avoid hampering effects of these differences on cross border electronic trade. Often such interfaces are procedural and formal rather than substantive. Some elements of International Private Law and also Safe Harbor Clauses point into the direction of evolving legal interfaces. From case to case these interfaces are tailored to facilitate electronic transactions and adapt to new technological developments. But these solutions have a tendency to work in favor of the Anglo-American legal tradition of common law and disfavor the continental 
European concept of law making, which proves to be too rigid and inflexible to cope with such problems.

\section{Conclusion: The Future Role of Law}

The examination of global communications regulation reveals that governments and other public actors have lost leverage as far as the provision and operation of the Internet and other technical infrastructure is concerned. In most cases the collaborative development of technical protocols and standards does not rely on governmental support and is carried out in a more efficient and effective way when political intervention is avoided. Frequently standardization is coordination and not regulation. From this angle it comes as no surprise that Internet standards have been global standards from the beginning.

Apparently global coordination is easier to achieve than global regulation. But there can be no doubt that also some kind of regulation is needed to facilitate the provision of electronic services on a global scale. Regulation is traditionally the domain of law. Thus, we might conclude, a global system of uniform legal regulations is best suited to govern international electronic transactions. But this general conclusion would be misleading. Legal as well as technical heterogeneity often spur competition and innovation, and therefore must be protected against pressures towards uniformity. Likewise legal regulations geared to facilitate cross border transactions need not be globally uniform. But they must be internationally transparent. The empirical analysis of regulatory efforts confirms this position. Initiatives based on the harmonization approach have consistently lost ground to different variants of private and public-private self-regulation, often employing technical procedures and solutions, and to regulatory strategies including dispute resolution mechanisms tailored to the specific types of cases.

Considering this development, what role will the law play in global communications in the future? At the first glance, this seems to be only a minor role. Technical developments will continue to set the framework of global communications. To a large extent, this framework will determine if and how regulatory measures can be applied and how their objectives can be achieved. As a consequence, technical "Code" (software) to put it in Lessig's terms "is Law" (Lessig, 1999) and technology based self-regulation appears to be barely influenced by the established legal system. But it does not exist in a legal vacuum either.

We observe efforts to provide a legal framework to shape and control self-regulation. In the case of self-regulated content-filtering legal regulation aims to ensure that these filters are not controlled by any single powerful company-a scenario which, considering global mergers such as the one of AOL/Time Warner, is not at all unlikely. While a filter system may be an adequate means to protect children from harmful violent and sexual content, the filter can at the same time be used by the system's vendor to control and influence the flow of information on the Internet and thus infringe upon the users' and content providers' freedom of speech and freedom of information. Legislation in this area continues to provide a binding framework that ensures that fundamental human rights can be freely exercised. It is only within this framework that one can rely on self-regulation. This kind of regu- 
lated self-regulation represents one significant trend in which law continues to play a crucial role.

Regulators have to acknowledge that even the most efficient technology based mechanism of self-regulation cannot stop certain individuals from refusing to accept the established framework. Criminal hackers, right wing extremists and people offering child pornographic content often find ways in the global Internet to circumvent and bypass the rules. The response to this problem is not adopting more or more detailed law in a national or regional context. What is evolving are pragmatic non-legal solutions tailored to the specific problem at the global level. They grant reputation to those public agencies and private corporations that act according to "best practices" and (morally) commit themselves to standards of conduct.

Where law is needed to regulate global communications-operation and use of technical infrastructure - this law will not be globally uniform, and only in a limited number of cases will it be regionally harmonized law. Rather different types of legal interfaces-formal and procedural rather than substantive-will guide network operation, service provision and commercial electronic transactions. The interfaces establish whose country or region's law applies in a specific case and make sure that the respective law is enforced across national borders. Interface law preserves national and regional autonomy in law making (Scharpf, 1994), it is compatible with a competitive economic world order, it increases rather than reduces users' options and it perfectly conforms to the organizational (de-centralized, global) and technical (heterogeneous and open) structure of the Internet.

\section{Notes}

*An earlier version of this article first appeared in Zeitschrift für Rechtssoziologie Bd.23/H1 July 2002.

\section{References}

Abbott, K.W. \& Snidal, D. (2000). "Hard and Soft Law in International Governance." International Organization, 54(3): 421-456.

Bertelsmann Stiftung. (1999). Verantwortung im Internet-Das Memorandum. Gütersloh, Bertelsmann Stiftung.

Burkert, H. (2000). "Privacy-Data Protection-A German/European Perspective." In C. Engel and K.H. Keller (eds.), Governance of Global Networks in the Light of Differing Local Values. BadenBaden, Nomos: 43-70.

Committee to Study Global Networks and Local Values, Computer Science and Telecommunications Board, National Research Council. (2001). Global Networks and Local Values: A Comparative Look at Germany and the United States. Washington, D.C.: National Academy Press.

Cowhey, P. and Richards, J. (2000). "Dialing for Dollar Institutional Designs for the Globalization of the Market for Basic Telecommunications Services." In Prakash, A. and Hart, J.A. (eds.), Coping with Globalization. London, Routledge: 148-169.

David, P.A. (1985). "Clio and the Economics of QWERTY." American Economic Review, 75: 332337.

Farrell, H. (2002). "Hybrid Institutions and the Law: Outlaw Arrangements or Interface Solutions?" Zeitschrift für Rechtssoziologie, 23(1): 25-40.

Genschel, P. and Werle, R. (1993). "From National Hierarchies to International Standardization: Historical and Modal Changes in the Governance of Telecommunications." Journal of Public Policy, 13(3): 203-225. 
Gillies, James \& Cailliau, R. (2000). How the Web was Born. The Story of the World Wide Web. Oxford, Oxford University Press.

Haufler, V. (2001). A Public Role for the Private Sector. Industry Self-Regulation in a Global Economy. Washington, D.C., Carnegie Endowment for International Peace.

Holtgrewe, U. and Werle, R. (2001). "De-Commodifying Software? Open Source Software between Business Strategy and Social Movement." Science Studies, 14(2): 43-65.

Holznagel, B. (1999). "New Challenges: Convergence of Markets, Divergence of the Laws? Questions Regarding the Future Communications Regulation." International Journal of Communications Law and Policy, Issue 2 (Winter 1998/1999). >http://www.digital-law.net/IJCLP/2_1999/ ijclp_webdoc_5_2_1999.html<

Holznagel, B. (2000). "Responsibility for Harmful and Illegal Content as Well as Free Speech on the Internet in the United States of America and Germany." In C. Engel and K.H. Keller (eds.), Governance of Global Networks in the Light of Differing Local Values. Baden-Baden, Nomos: $9-42$.

Holznagel, B., Enaux, C., and Nienhaus, C. (2001). Grundzüge des Telekommunikationsrechts: Rahmenbedingungen, Regulierungsfragen, internationaler Vergleich. München, C.H. Beck.

Knill, C. and Lehmkuhl, D. (2002). "Private Actors and the State: Internationalization and Changing Patterns of Governance." Governance, 15(1): 41-63.

Krasner, S. D. (1991). "Global Communications and National Power. Life on the Pareto Frontier." World Politics, 43: 336-366.

Leib, V. and Werle, R. (1998). "Computernetze als Infrastrukturen und Kommunikationsmedien der Wissenschaft." Rundfunk und Fernsehen, 46(2-3): 254-273.

Leibenstein, H. (1984). "On the Economics of Conventions and Institutions: An Explanatory Essay." Zeitschrift für die gesamte Staatswissenschaft (Journal of Institutional and Theoretical Economics), 140: 74-86.

Lessig, L. (1999). Code and Other Laws of Cyberspace. New York, Basic Books.

Mueller, M. (2000). "Technology and Institutional Innovation: Internet Domain Names." International Journal of Communications Law and Policy, 5 (Summer 2000). >http://www.digital-law.net/ IJCLP/5_2000/ijclp_webdoc_1_5_2000.html<

Mueller, M. (2002). Ruling the Root. Internet Governance and the Taming of Cyberspace. Cambridge, MA, The MIT Press.

Norberg, A.L. and O'Neill, J. (1996). Transforming Computer Technology. Information Processing for the Pentagon, 1962-1986. Baltimore, The Johns Hopkins University Press.

Osthaus, W. (2000)."Local Values, Global Networks, and the Return of Private Law-On the Function of Civil Law and Private International Law in Cyberspace." In C. Engel and K.H. Keller (Eds.): Governance of Global Networks in the Light of Differing Local Values. Baden-Baden, Nomos: 209-236.

Ostrom, E. (1990). Governing the Commons: The Evolution of Institutions for Collective Action. Cambridge, Cambridge University Press.

Peritt, H.H. (1996, Supplements). Law and the Information Superhighway. Frederick, Aspen Law \& Business.

Resnick, P. and Miller, J. (1996). "PICS: Internet Access Controls without Censorship." Communications of the ACM, 39(10): 87-93.

Ronit, K. and Schneider, V. (2000). "Private Organizations and Their Contribution to Problem-Solving in the Global Arena." In K. Ronit and V. Schneider (eds.): Private Organizations in Global Politics. London, Routledge: 1-33.

Scharpf, F.W. (1994). "Community and Autonomy: Multi-Level Policy-Making in the European Union." Journal of European Public Policy, 1(2): 221-242.

Schmidt, S. \& Werle, R. (1998). Coordinating Technology. Studies in the International Standardization of Telecommunications. Cambridge, MA, The MIT Press.

Snidal, D. (1985). "Coordination versus Prisoners' Dilemma: Implications for International Cooperation and Regimes." American Political Science Review, 85: 702-726.

Stein, A.A. (1990). Why Nations Cooperate: Circumstance and Choice in International Relations. Ithaca, Cornell University.

Weinberg, J. (1997). "Rating the Net." In G.L. Rosston and D. Waterman (eds.), Interconnection and the Internet. Mahwah, NJ, Lawrence Erlbaum: 225-242. 
Werle, R. (1995). Staat und Standards. In Renate Mayntz and Fritz W. Scharpf (eds.): Gesellschaftliche Selbstregelung und politische Steuerung. Frankfurt a.M., Campus: 266-298.

Werle, R. (2001a). "Liberalisierung und politische Techniksteuerung." Politische Vierteljahresschrift, 41 (Sonderheft 31/2000: Politik und Technik): 407-424.

Werle, R. (2001b). "Institutional Aspects of Standardization-Jurisdictional Conflicts and the Choice of Standardization Organizations." Journal of European Public Policy, 8(3): 392-410.

Werle, R. (2001c). "Standards and Standards Organizations in the International Free Trade Regime." Knowledge, Technology, \& Policy, 14(3): 127-140. 